\title{
Strategi Intergrated Marketing Communication Bioskop Platinum Cineplex Solo dalam Menarik Minat Penonton
}

\author{
Nurul Khotimah \\ Prodi Ilmu Komunikasi Universitas Islam Indonesia, Yogyakarta \\ Ratna Permata Sari \\ Prodi Ilmu Komunikasi Universitas Islam Indonesia, Yogyakarta
}

\begin{abstract}
ABSTRAK
Banyaknya bioskop di Indonesia, antara lain Cinema 21, XXI, Blitzmegaplex, Platinum Cineplex. melahirkan persaingan untuk menarik minat penonton. Tujuan penelitian ini adalah mengetahui strategi Integrated Marketing Communications (IMC) yang dilakukan pada bioskop Platinum Cineplex Solo dalam menarik minat penonton. Dengan menggunakan metode deskriptif kualitatif, penelitian ini menunjukkan bahwa untuk menarik penonton, Platinum Cineplex melakukan proses pemasaran yang dimulai dari analisis peluang, analisis kompetitor, segmentasi pasar, menentukan harga, distribusi, promosi, kinerja karyawan, proses, lingkungan fisik. Beberapa kegiatan promosi yang dilakukan Platinum Cineplex adalah kegiatan yang menunjang keputusan promosi, aktivitas promosi penjualan, hubungan masyarakat, pemasaran langsung dan sponsorship.
\end{abstract}

Kata kunci: Pemasaran, Integrated Marketing Communications, Bioskop Platinum Cineplex

\begin{abstract}
The growing number of Indonesian cinema theaters, such as Cinema 21, XXI, Blitzmegaplex, Platinum Cineplex, was demanding the competition to attract the viewers. The purpose of this study is to describe the strategy of Integrated Marketing Communications (IMC) performed by Platinum Cineplex Cinema Solo in attracting audiences. Doing the qualitative research, this study indicates that Platinum Cineplex Cinema Solo performed marketing process starting from opportunity analysis, competitor analysis, market segmentation, pricing, distribution, promotion, employee performance, process, physical environment. Promotion strategy did by Platinum Cineplex Solo include promotion decision activity, sales promotion, public relations personnel sales, direct marketing and sponsorship.
\end{abstract}

Keywords: marketing, integrated marketing communication, theater, Platinum Cineplex 


\section{Pendahuluan}

Persaingan industri hiburan saat ini semakin ketat. Bioskop adalah salah satu hiburan yang diminati masyarakat. Berkembangnya dunia perfilman dan minat penonton film di Indonesia ini menyebabkan banyaknya bioskop yang berdiri di Indonesia. Jaringan bioskop yang berdiri di Indonesia diantaranya Cinema 21, XXI, Blitzmegaplex, Platinum Cineplex.

Namun, seiring berjalannya waktu dan perkembangan teknologi yang ada saat ini, minat masyarakat untuk menonton bioskop mengalami penurunan. Data penonton film di Indonesia sejak tahun 2012 sampai tahun 2014 cenderung menurun. Enam belas juta penonton pada tahun 2012 menurun pada tahun 2013 menjadi 15,5 juta penonton. Pada tahun 2014, jumlah penonton bioskop kembali mengalami penurunan menjadi 14,1 juta penotnon. (Muvila, 2015).

Dibandingkan dengan Cinema 21 dan Blitzmegaplex, Platinum Cineplex merupakan bioskop yang baru. Platinum Cineplex merupakan manajemen group dari multivison plus. Platinum Cineplex di Indonesia terdapat di empat kota yaitu Cibinong, Solo, Sidoarjo dan Magelang. Di Cibinong bioskop ini cukup sukses, sedangkan di kota lainya termasuk pendatang baru. Di Solo lokasi bioskop ini berada di dalam Hartono Mall sejak 11 Desember 2013 yang bertepatan dengan peluncuran pertama film Soekarno.
Sebagai bioskop baru, Platinum Cineplex Solo ini mempunyai kekurangan dan kelebihan. Kelebihan dari bioskop Platinum Cineplex Solo dibanding dua bioskop pendahulunya yang paling terlihat adalah memberikan tiket yang murah dengan fasilitas yang sama seperti bisokop lainnya. Kelebihan lain adalah terintegrasinya ruang pertunjukan film dengan pusat perbelanjaan. Ketiga hal ini menjadi hal yang menarik.

Disisi lain, Platinum Cineplex masih harus banyak membenahi kekurangan yang ada diantaranya fasilitas tempat duduk yang masih kurang nyaman serta layar yang perlu diperlebar dan kualitas sound system yang tidak terlalu baik sehingga kekurangan Platinum Cineplex ini menjadi koreksi untuk lebih baik lagi.

Berkaca pada tumbangnya bisnis bioskop-bioskop lokal yang pernah ada, setiap perusahaan harus memiliki strategi pemasaran dan kebijakan untuk mampu menjaga eksistensi perusahaan tersebut. Oleh karena itu penelitian ini tertarik untuk mengetahui Strategi Intergrated Marketing Communication bioskop Platinum Cineplex Solo dalam menarik minat penonton.

\section{Tinjauan pustaka}

1. Proses Pemasaran

Proses pemasaran dimulai dengan mempersiapkan rencana strategi pemasaran dan analisis pemasaran yang akan digunakan dalam memutuskan 
produk yang akan dihasilkan dan pasar atau konsumen yang akan dituju. Perusahaan kemudian harus mengoordinasikan berbagai elemen bauran pemasaran ke dalam suatu program pemasaran kohesif yang akan menjangkau target pasar secara efektif.

Philip Kotler dan Gary Amstrong mendefinisikan Integrated Marketing
Communication (IMC) sebagai konsep dimana suatu perusahaan secara hati-hati mengintegrasikan dan mengkoordinasikan saluran komunikasinya yang banyak untuk menyampaikan pesan yang jelas, konsisten dan meyakinkan mengenai perusahaan dan produknya (Kotler \& Amstrong, 2001: 38)

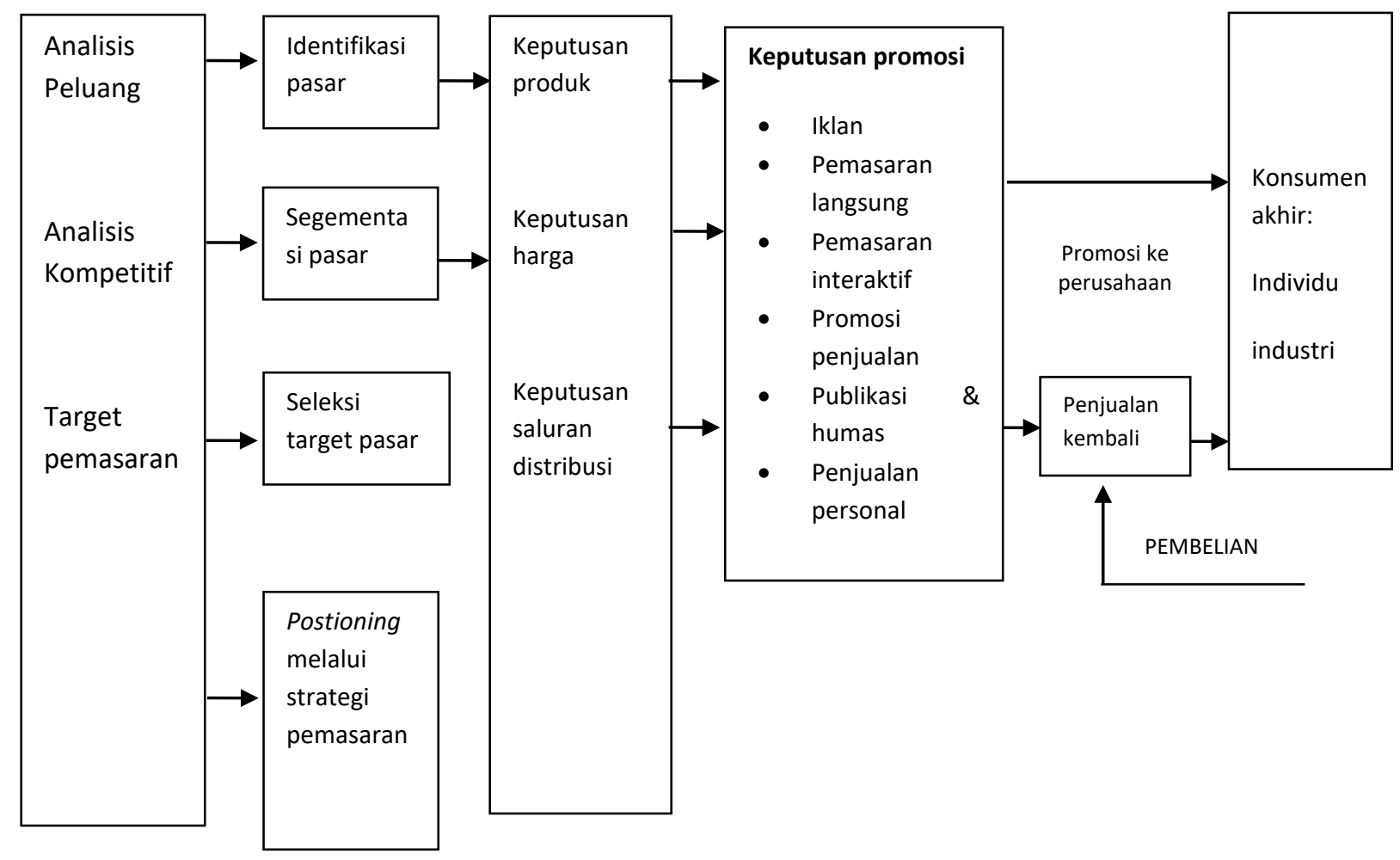

(Morissan, 2010:49)

Tabel 1 .Model Proses Pemasaran dan Promosi

2. Bauran Pemasaran (Marketing Mix)

Dalam pemasaran produk barang, analisis biasanya menggunakan strategi ${ }_{4} \mathrm{P}$ yaitu Place, Product, Promotion dan Price. Penelitian ini berkonteks pada strategi pemasaran bidang jasa, sehingga lebih tepat menggunakan konsep marketing mix untuk jasa yaitu konsep $7 \mathrm{P}$ antara lain: keputusan produk (Product), keputusan harga (Price), Place, People, Process, Physical Evidence, Promotion. 


\section{Bauran Promosi}

Walaupun komunikasi antara perusahaan dan konsumen secara implisit berlangsung pada setiap unsur dari marketing mix sebagaimana telah dijelaskan sebelumnya, namun sebagian besar komunikasi perusahaan berlangsung sebagai bagian dari suatu program promosi yang diawasi dan direncanakan dengan hati-hati. Instrumen dasar yang digunakan untuk mencapain tujuan komunikasi perusahaan disebut dengan bauran promosi atau promotional mix, yaitu antara lain sebagai berikut.

\section{Advertising/periklanan}

Periklanan adalah setiap transaksi yang menggambarkan aktifitas non personal dengan upaya menawarkan ide, barang dagangan dan jasa sesuai yang diingkinkan sponsor tertentu yang dibayar (Lee dan Johson, 2004:3).

\section{Promosi penjualan}

Promosi penjualan adalah sebuah kegiatan atau materi yang bertindak sebagai ajakan, memberikan nilai tambah atau insentif untuk membeli produk kepada para pengecer, penjual, atau konsumen (Lee dan Johson 2004: 331)

\section{Public relations}

4. Personal selling/penjualan personal

Personal selling merupakan alat yang paling efektif pada tahapan Selnajutnya yaitu proses pembelian, khusunya untuk membangun preferensi, keyakinan, dan mendorong (Sulaksana (2007: 28).
5. Pemasaran langsung

Dalam pemasaran langsung, komunikasi promosi ditujukan langsung kepada konsumen individual, dengan tujuan agar pesan-pesan tersebut ditanggapi konsumen yang bersangkutan (Kotler, 2007: 290).

\section{Sponsorship}

Sponsorship merupakan pemberian dukungan keuangan atau bentuk-bentuk dukungan lainnya kepada pihak penerima agar keungan si penerima tetap lancar atau menjadi lebih kokoh serta dapat membangun citra postif terhadap merek.

\section{Metode Penelitian}

Jenis penelitian ini adalah deskriptif yang menggunakan pendekatan kualitatif dan menganut paradigma konstruktivisme. Penelitian ini menjelaskan realitas apa adanya tanpa ada yang diubah. Penelitian menganalisis dan menuliskannya sesuai dengan apa yang dilihat lewat observasi dan juga apa yang didapat lewat wawancara dan dokumen-dokumen yang didapat (Salim, 2006: 89). Penelitian ini dilakukan pada tanggal 1 Desember 2015 sampai dengan 20 April 2016 yang bertempat di Bioskop Platinum Cineplex yang masih dalam satu kawasan di dalam Mall Hartono Solo.

Narasumber dipilih dengan menggunakan purposive sampling yaitu teknik sampling yang digunakan peneliti jika memiliki pertimbanganpertimbangan tertentu dalam sampelnya. 
(Idrus, 2009:96). Pemilihan narasumber yang menjadi objek penelitian ini berdasarkan pada jabatan yang bersangkutan maupun pihak-pihak dalam Platinum Cineplex Solo yang berkompeten dalam menunjang penelitian ini seperti pada bagian Manajemen Pemasaran yaitu Danang Prabowo. Adapun untuk teknik pengumpulan data yaitu melalui observasi, wawancara mendalam dan studi pustaka.

\section{Hasil dan Pembahasan}

Berikut adalah penjelasan mengenai strategi komunikasi pemasaran yang dilakukan oleh Platinum Cineplex dalam upaya meningkatkan kepuasan dan loyalitas konsumen terhadap pelayanan yang diberikan oleh Platinum Cineplex.

Dalam penentuan analisis peluang ini, Platinum Cineplex sangat berhati-hati karena penentuan yang asal-asalan bisa menyebabkan kegagalan produk atau jasa yang ditawarkan dihadapan masyarakat. Oleh karena itu, Platinum Cineplex sudah melakukan observasi dan juga melihat hasil survei sebelumnya. Salah satu survei yang dijadikan pijakan adalah survei Kota Solo yang menyebutkan bahwa Kota Solo berkembang semakin pesat. Selanjutnya, melihat banyaknya perusahaan internasional di Solo. Platinum Cineplex memilih membuka di bioskop pinggiran, tidak di tengah kota karena Platinum tidak mau head to head dengan bioskop lainnya karena jika demikian Platinum mungkin tidak survive.
Memilih tempat dalam memenangkan persaingan di pasar agar mendapatkan pengiklan dan penonton bukanlah hal yang mudah. Oleh karena itu Platinum Cineplex berusaha melakukan peluang pasar di Kota Solo agar dapat menarik penonton sebanyak mungkin yang ada di wilayah Solo dan sekitarnya. Selanjutnya, menentukan analisis kompetitif dan target pasar. Analisis kompetitif suatu hal khusus yang dimiliki atau dilakukan perusahaan yang memberikannya keunggulan dibandingkan kompetitor.

Strategi yang terpenting dalam melakukan persaingan adalah promotion mix yanag terdiri dari product, price, place, promotion, people, proces, physical evidence. Produk berfungsi sebagai sesuatu yang akan dijual oleh perusahaan media tersebut, karena produk ini harus dapat dijual ke konsumen yang merupakan titik akhir pemasaran. Oleh sebab itu, dalam menghasilkan produknya, Platinum Cineplex, harus memperhatikan selera penonton berdasarkan kualitas atau mutu produk itu sendiri. Bukanlah hal yang mudah dalam menaklukkan bioskop tersebut karena segmen mereka sudah berbentuk secara apik dan kuat.

Dalam hal isi, film yang ditawarkan oleh Platinum Cineplex yaitu dengan disajikan film-film Thailand, India yang sangat jarang ditemui di bioskop yang ada di Indonesia. Film Thailand dan India mempunyai segmen masyarakat 
yang cenderung ke usia produktif dari umur 18-30 tahunan. Mutu produk yang didasarkan pada bioskop Platinum Cineplex Solo adalah dengan film-film yang menarik disertai dengan edukasi, membuat Platinum Cineplex banyak yang ingin menonton film di bioskop tersebut.

Penentuan harga merupakan salah satu keputusan yang penting bagi manajemen. Harga yang ditetapkan harus menutup semua ongkos atau bahkan lebih dari itu memberikan laba perusahaaan. Platinum Cineplex Solo mengalami perubahan harga dalam perjalanannya karena disesuaikan dengan perkembangan strategi untuk memanangkan konsumen. Pada tahun pertama, 2012, memberikan harga promosi Rp.1500o,- per tiket + popcorn dan soft drink setiap hari kepada konsumen. Hal ini untuk menarik perhatian konsumen, karena Platinum Cineplex Solo merupakan bioskop yang baru.

Pada tahun 2015 bulan Agustus, Platinum Cineplex Solo menerapkan tarif Rp 25.000 + soft drink karena ditegur oleh pihak distributor. Distributor memprotes tarif tersebut karena terlalu murah dalam masa waktu yang cukup lama. Dengan menaikkan harga $\mathrm{Rp}$ 25.000, tidak berpengaruh bagi pendapatan yang didapat. Strategi yang dilakukan Platinum Cineplex masih sama seperti dulu mengutamakan pelayanan dan film yang ditayangkan.
Platinum Cineplex ini merupakan ekspedisi bioskop dari multivisions plus yang bioskopnya sudah terkenal lebih dahulu diluar negeri, diantaranya negara Vietnam, Laos, Kamboja dan Singapore. Lalu, Platinum Cineplex mencoba membuka bioskop di Indonesia karena melihat potensi minat menonton dalam bioskop sangat tinggi. Memilih tempat di Indonesia bukan di daerah ibu kota melainkan di daerah-daerah pinggir, misalnya Cibinong, Solo, Magelang, dan Sidoarjo.

Promosi bioskop memainkan peran penting dalam program pemasaran untuk membangun dan mempertahankan permintaan terhadap produk tidak saja kepada konsumen akhir tetapi juga kepada distributor film. Promosi meliputi semua kegiatan yang dilakukan perusahaan untuk mengkomunikasikan dan mempromosikan produknya kepada pasar sasaran.

Promosi yang dilakukan oleh Platinum Cineplex sudah berjalan sejak dibukanya bioskop Platinum Cineplex pada tahun 2013, promosi yang dilakukkan oleh Platinum Cineplex diantaranya periklanan dengan berbagai empat media yaitu media indoor dengan pemasangan poster di dalam sudut lingkungan hartono mall, media cetak Koran Joglosemar dengan memasang iklan jadwal film yang ditayangkan, media elektronik memasang iklan spot di radio suara meta dan solo radio yang diputar pada jam 3 sore, dan yang terakhir media 
internet di facebook dan twitter. Promosi penjualan juga dilakukkan Platinum Cineplex dengan cara menawarkan tiket murah, pemasaran langsung dengan memasarkan produk platinum cineplex kepada instasi di pergurungan tinggi, sponsorship dengan bekerjasama dengan pihak organisasi pemerintah yaitu PMI.

Bioskop dituntut menciptakan sebuah persepsi yang positif dari audien sebagai upaya untuk menjaga loyalitas audien. Hal inilah yang nantinya menciptakan citra produk (brand image) positif yang mendukung dengan loyalitas audien bagi sebuah media massa, sehingga mampu tetap eksis di industri media massa.

Dalam melaksanakan strategi komunikasi pemasaran, semua karyawan Platinum Cineplex juga dituntut untuk menjaga sikap ramah pada konsumen dan cara berpakaian karyawan serta penampilan karyawan memiliki pengaruh terhadap keberhasilan penyampaian jasa.

Untuk itu, Platinum Cineplex Solo sangat teliti dalam memilih SDM, SDM yang dipilih adalah orang-orang yang mau diajak untuk berkerjasama dalam membangun Platinum Cineplex lebih baik. SDM yang terpilih diseleksi langsung dari kantor pusat.
Pengelola usaha bioskop Platinum Cineplex menawarkan berbagai macam bentuk pelayanan tujuan menarik konsumen secara langsung. Proses dengan cara penyampaian informasi terbaru kepada konsumen, memberikan fasilitas jasa konsultasi gratis dalam hal ini terkait dengan komplain para konsumen saat berada di lingkungan Platinum Cineplex, misalnya adanya kesalahan jam tayang pada tiket atau sound system kurang jelas pada pemutaran film. Disini, konsumen bisa memberikan masukan untuk platinum tujuannya mengembangkan Platinum Cineplex lebih baik.

Mengingat bahwa penggerak perusahaaan bioskop Platinum Cineplex Solo baru maka untuk menjamin mutu layanan seluruh operasional Platinum Cineplex harus dijalankan sesuai dengan sistem dan prosedur yang terstandarisasi oleh karyawan yang berkompetensi, berkomitmen, dan loyal terhadap perusahaan tempatnya bekerja.

Bagi Platinum Cineplex Solo, penerapan 'physical evidence' ini adalah pada pemilihan lokasi bioskop. Sebagai produk premium, Platinum Cineplex Solo memilih untuk membuka bioskop ditempat eksklusif yang berada di pusat perbelanjaan di kota Solo disebut (Hartono Mall). Tidak hanya itu, Hartono Mall juga siap membantu melayani konsumen dan mendukung adanya bisokop Platinum Cineplex di Mall tersebut. 


\section{Komunikasi Pemasaran Terpadu (Integrated Marketing Communication)}

Adapun strategi Integrated Marketing Communication yang dilakukan Platinum Cineplex Solo untuk menarik minat penonton adalah sebagai berikut.

\section{Periklanan (Advertising)}

Berbagai jenis media periklanan yang digunakan oleh bioskop Platinum Cineplex, telah menunjukan bahwa perusahaan tersebut cukup memperhatikan media apa saja yang akan digunakan pada strategi komunikasi pemasaran. Dibawah ini adalah media periklanan apa saja yang dilakukan oleh bioskop Platinum Cineplex Solo dalam menarik minat penonton:

Strategi periklanan yang dilakukan bioskop Platinum Cineplex untuk menarik minat penonton menggunakan strategi indoor. Media indoor yaitu pemasangan poster tujuannya adalah sebagai pengingat dan secara tidak langsung mengajak khalayak untuk menjadi pelanggan.. Poster dipasang di area basement di lingkungan Hartono Mall. Iklan poster dan yang dilakukan Platinum Cineplex merupakan iklan yang berisikan tentang informasi harga tiket yang murah. Iklan poster tersebut merupakan hasil kerja sama antara pihak bioskop Platinum Cineplex dan Hartono Mall Solo, dimana Platinum Cineplex menjadi partner dalam hal pelaksanaan dan pembiayaan.
Iklan poster tersebut secara umum berisikan seputaran harga tiket murah seperti "Harga Hemat Tiket Bioskop+popcorn+soft drink= hanya Rp. 15.00o,-." Pemasangan poster ini dilakukan di wilayah Hartono Mall Solo. Poster yang dipasang di wilayah Hartono Mall cukup merata di seputaran tiap lantai yang ada di Hartono Mall.

Platinum Cineplex memasang iklan di beberapa radio diantaranya Radio Suara Meta Fm dan Solo Radio Fm. Kedua radio tersebut segmennya samasama usia yang masih produktif. Selain itu, pendengarnya masih aktif dalam mendengarkan siaran, dan radio yang lumayan segementasi pendengarnya dikota Solo. Platinum Cineplex menjalin kerja sama dengan Radio Suara Meta dan Solo Radio dengan mensiarkan apa saja program yang lagi hangat di Platinum Cineplex setiap hari pada jam 3 sore bentuk iklan radio yang ada di Suara Meta dan Solo radio spot dan adlips iklan kurang lebih 5-10 kali perhari radio lokal tersebut. Pendengarnya merupakan mahasiswa yang sering mendengarkan acara di sore hari.

Platinum Cineplex melakukan kerjasama dengan Koran Joglosemar yang bentuk kerjasamanya adalah Platinum Cineplex melakukan iklan informasi penayangan jadwal film yang saat diputar yang dimuat dikolom halaman iklan pada Koran Joglosemar. 
Dalam pemasangan iklan di media cetak, Platinum Cineplex memilih Koran Joglosemar, Alasan memilih koran tersebut karena koran tersebut koran yang sering banyak minat pembaca di Solo, serta respon dari Joglosemar sangat bagus, misalnya kalau ada film yang bagus yang lagi ditayangkan lalu banyak yang penonton suka dijadikan rubik khusus setengah kolom halaman

Dalam majalah Lifestyle Solo, terdapat iklan platinum yang mencantumkan riview dari Film Avengers serta keseruan dari penonton penggemar film Avengers harga tiket nonton di Platinum Cineplex. Hal ini menunjukan bahwa Platinum Cineplex mempunyai tempat di hati masyarakat Solo dan wartawan.

Platinum Cineplex menggunakan beberapa media internet sebagai alat komunikasinya untuk beriklan yaitu: Facebook dan Twitter karena facebook dan twitter sangat fleksibel infomasinya dan murah sehingga sebagaian orang banyak yang mengetahui Platinum Cineplex.

Halaman dinding komentar facebook Platinum Cineplex terdapat komentar masyarakat tentang masukan yang positif untuk membangun Platinum Cineplex lebih baik lagi. Disini komentar masyarakat langsung cepat dipublikasikan dan diberi tanda bintang agar memudahkan Platinum Cineplex untuk memperbaiki kesalahan yang ada.
Twitter Platinum Cineplex mempunyai 19,8 k followers, banyaknya followers berarti Platinum Cineplex sangat diterima di masyarakat. Tidak hanya jadwal film saja yang di tampilkan, tetapi adanya tweet yang lucu untuk ditampilkan setiap hari kepada followers sehingga membuat followers tidak bosan yang melihat timeline twitter Platinum Cineplex.

2. Promosi Penjualan

Paket yang ditawarkan oleh Platinum Cineplex lebih murah dibanding dengan biokop lainnya, dengan harga $\mathrm{Rp}$ 25.00o sudah bisa mendapatkan tiket nonton dan soft drink. Pada tahun 2013, pertama kalinya (grand opening) bioskop Platinum Cineplex menjual tiket dengan harga $\mathrm{Rp}$ 15.0oo sudah dapat tiket nonton film, soft drink+popcorn. Pertengahan tahun 2015 harga tiket Rp 15.000 naik menjadi Rp 25.00o dikarenakan di tegur oleh distributor karena paket yang ditawarkan murah dalam jangka waktu yang cukup lama. Adanya promo ini tiket bisa terjual dengan 1000-1500 tiket setiap harinya. Dengan demikian bahwa terbukti bahwa promosi penjualan dapat meningkatkan penjualan tiket.

Sementara itu, Platinum Cineplex aktif melakukan promosi penjualan dalam bentuk bermacam-macam, antara lain pemberian tiket murah ditambah dengan popcorn atau softdrink. Diskon biasanya diberikan pada saat program tertentu misalnya acara ulang tahun Platinum 
Cineplex memberikan tiket gratis dan souvenir kepada pengunjung yang melakukan transaksi di Platinum Cineplex. Lama program promo diskon tersebut berlangsung biasanya relatif tergantung situasi dan bentuk kerjasamanya.

3. Hubungan Masyarakat (Public Relations)

Platinum Cineplex menjalin kerjasama dengan artis dalam acara meet and greet dan melakukan press release kepada pers. Press release ditulis dan dikirimkan oleh Manager Marketing kepada koran-koran lokal di Solo. Respon yang diterima oleh pers kepada Platinum Cineplex cukup positif karena hampir setiap prees release yang dikirimkan oleh pihak Platinum Cineplex selalu dimuat oleh media tersebut.

\section{Personal Selling/ Penjualan personal}

Strategi penjualan personal yang dilakukan Platinum Cineplex Solo dalam upaya menarik penonton mencakup strategi yakni presentasi promosi program dan promosi harga tiket. Presentasi promosi dengan memberikan workshop kepada mahasiswa-mahasiswi untuk menyampaikan beberapa point penting seperti menginformasikan film-film dokumenter yang mahasiswa bisa memutarnya di Platinum Cineplex serta memperkenalkan produk Platinum Cineplex Solo. Dari presentasi promosi tersebut, tidak lupa dengan menginformasikan terkait harga tiket menonton di Platinum Cineplex.

\section{Pemasaran Langsung}

Dalam pemasaran langsung yang dilakukan Platinum Cineplex, mengerahkan divisi marketing secara khusus bertugas sebagai direct seller Platinum Cinepelx. Cara memasarkannya adalah mendata calon konsumen yang akan ikut serta dalam kerjasama dengan Platinum Cineplex Solo. Selanjutnya, Platinum Cineplex mendatangi ke sekolah, komunitas film, serta perusahaannya dengan memperkenalkan produk Platinum itu sendiri. Divisi marketing akan mengonfirmasi terhadap konsumen yang sudah didatangi oleh pihak Platinum Cineplex dengan cara menelepon atau direct mail kepada salah satu konsumen lalu menegosiasi apakah mau diajak kerjasama atau tidak. Setelah mereka tertarik langkah selanjutnya pihak Platinum Cineplex membuat MoU Tujuannya agar menarik konsumen yang ingin menonton di Platinum Cineplex serta menjadikan Platinum Cineplex sebagai brand image di benak masyarakat bahwa Platinum Cineplex bioskop yang berbeda dengan bioskop lainnya di kota Solo.

6. Sponsorship

Dalam kegiatan sponsorship, Platinum Cineplex Solo berpartisipasi dalam memberikan hadiah tiket nonton 
dalam acara meet and greet dalam rangka peluncuran film hijabers. Melalui acara ini Platinum Cineplex berpartisipasi dalam memberikan tiket nonton gratis bagi konsumen yang melakukan sesi tanya jawab pada acara tersebut. Platinum Cineplex tidak menemui kendala dalam kegiatan sponsorship ini.

\section{Kesimpulan}

Proses pemasaran sebuah bioskop dituntut untuk dapat merumuskan, menciptakan, menentukan harga, mendistibusikan dan memasarkan produknya dengan baik. Namun, pada perkembangannya sebuah bioskop dituntut untuk melalui strategi komunikasi pemasaran kepada target sasarannya.

Produk Platinum Cineplex ini menampilkan film-film yang tidak ditayangkan di bioskop lainnya seperti film thailand, india serta dokumentar dengan harga tiket nonton yang lebih murah dibandingkan bioskop lainnya harga tiket Rp $25000+$ popcorn/softdrink, di dukung oleh kinerja karyawan yang ramah pada pengunjung, menampilkan film-film pilihan dari multivision plus. Pemilihan tempat yang strategis berada di tempat pusat perbelanjaan yang ada di Solo (Hartono Mall) membuat Platinum Cineplex di kenal diberbagai kalangan masyarakat mulai dari kalangan kebawah hingga keatas.
Strategi yang pertama dalam keputusan promosi yaitu strategi periklanan Platinum Cineplex menggunakan empat media. Pertama, media indoor yang dilakukkan Platinum Cineplex yaitu memasang poster di lingkungan Hartono Mall, pihak mall sendiri sangat mendukung pemasangan poster karena platinum sendiri tallent dari mall tersebut. Kedua, media cetak di koran Joglosemar sistem kerjasama dengan sistem menayangkan informasi populer yang sedang berlangsung di Platinum Cineplex dan menampilkan jadwal film di kolom iklan. Ketiga, Media elektronik di radio Suara Meta dan Solo Radio yaitu dengan sistem menampilkan iklan disaat jam santai yaitu jam tiga sore dimana banyaknya yang mendengarkan radio terutama anak muda. Terakhir, media internet menggunakan media sosial Facebook dan Twitter karena target market platinum sendiri yaitu anak muda, keluarga. Media internet ini sangat cocok untuk beriklan karena banyaknya anak muda yang mengakses media sosial ini.

Strategi kedua keputusan promosi yang dilakukan oleh bioskop Platinum Cineplex adalah promosi penjualan. strategi ini mencakup tiga cara, yaitu: 1) menggandeng orang komunitas, platinum bisa menampilkan film dokumentar yang dibuat oleh karya komunitas film indie sehingga masyarakat yang ingin karya filmnya di tonton di bioskop bisa menghubungi platinum dengan harga yang terjangkau. 2) media online dan 
radio. Kedua media ini sangat berperan penting dalam promosi penjulan dikarenakan banyaknya orang yang masih aktif dalam siaran radio dan media online di Kota Solo, sehingga masyarakat mengetahui Platinum Cineplex dari media tersebut.3) paket yang ditawarkan lebih murah dengan bisokop lainnya, dengan harga Rp. 25.000 masyarakat bisa menikmati film sekaligus minuman atau popcorn yang dibagikan secara gratis.

Strategi yang ketiga, yaitu hubungan masyarakat. Platinum Cineplex menjalin kerjasama dengan artis dalam acara meet and great dan melakukan press release kepada pers. Press release ditulis dan dikirimkan oleh Manager Marketing kepada koran-koran lokal di Solo.

Strategi yang keempat yaitu pemasarang langsung (direct marketing), yaitu melakukan presentasi dengan sekolah, kampus, untuk memasarkan produk atau program apa saja yang ada di Platinum Cineplex.

Keputusan promosi Platinum Cineplex Solo juga terlibat dalam kegiatan sponsorship, yaitu dengan berpartisipasi dalam memberikan hadiah tiket nonton dalam acara meet and greet dalam rangka peluncuran film hijabers.

\section{Daftar Pustaka}

Idrus, Muhammad. Metode Penelitian Ilmu Sosial. Yogyakarta: Erlangga. 2009.

Kotler, Philip. Manajemen Pemasaran. Klaten : PT Indeks Kelompok

Gramedia, 2000.

Kotler, Phillip dan Gary Amstrong. Prinsip-Prinsip Pemasaran. Edisi ke-8, Jakarta : Penerbit Erlangga, 2001.

Kotler, Philip. Manajemen pemasaran. Edisi kesebelas, jilid 2. Jakarta: PT Indeks Kelompok Gramedia, 2005.

Morissan. Komunikasi Pemasaran Terpadu. Edisi pertama. Jakarta: Kencana, 2010

Salim, Agus. Teori dan Paradigma. Yogyakarta: Tiara kencana, 2006.
Sulaksana, Uyung. Intergated Marketing Comunications Teks dan Kasus. Yogyakarta: Pustaka pelajar, 2007.

Suryabrata, Sumardi. Metodologi Penelitian. Jakarta: Raja Grofindo, 2003.

Tjiptono, Fandy. Strategi Pemasaran. Yogyakarta: ANDI, 1997.

Muvila. 2015. Catatan Perihal Turunnya Jumlah Penonton Film Indonesia. http://www.muvila.com/film/ artikel/catatan-perihalturunnya-jumlah-penontonfilm-indonesia-150504f.html, akses 11 Desember 2015. 